\title{
$\mathrm{NUI}$ 가 적용된 체감형 게임의 사용자 심전도 분석에 의한 스트레스 측정 알고리즘 연구
}

\author{
이현주, 신동일, 신동규 \\ 세종대학교 컴퓨터공학과 \\ nedkelly@gce.sejong.ac.kr, \{dshin, shindk\}@sejong.ac.kr
}

\section{A Study on a Stress Measurement Algorithm Based on ECG Analysis of NUI-applied Tangible Game Users}

Hyun-Ju Lee, Dong-II Shin, Dong-Kyoo Shin

Dept. of Computer Engineering, Sejong University

\begin{abstract}
요 약
NUI(Natural User Interface)는 별도의 입출력 장치 없이 사용자 자신의 음성/신체부위 등을 사용하여 주변 디지털 기기를 제어할 수 있도록 하는 기술이다. 본 논문에서는 NUI가 적용된 스마트 공간에서 신체를 직접적으로 사용하는 체감형 게임을 실행하는 사용자를 대상으로 연구 를 진행하였다. 게임 사용자의 스트레스 발생 여부를 알아내기 위하여 게임 시행 전과 후로 나 누어 각각 60 초에 걸쳐서 심전도를 측정하였고, 측정된 신호를 개량된 Random Forest 알고리 즘으로 분석하였다. 교사학습 방식에 의한 실험을 위하여 사용자는 자신의 스트레스 발생 여부 를 별도로 입력하여 저장하도록 하였으며, 실험결과 개량된 알고리즘이 기존의 알고리즘보다 $1.04 \%$ 높은 정확도를 보여주었다.
\end{abstract}

\section{ABSTRACT}

NUI(Natural User Interface) allows users to directly interact with surrounding digital devices using their voices or body motions without additional input/output interface devices. Our study has been carried out on human users who play a tangible game with body motions in the NUI-applied smart space. ECG was measured for 60 seconds duration before and after playing the game to determine user stress levels, and the measured signals were analyzed through an improved Random Forest algorithm. In order to experiment by a supervised learning, users additionally input whether or not the user felt stress. Moreover, the improved algorithm showed $1.04 \%$ higher accuracy than existing algorithm.

Keywords : Tangible Game(체감형 게임), NUI(Natural User Interface), ECG(심전도), Stress(스트레스), Random Forest, Algorithm(알고리즘), Accuracy(정확도)

Received: Jul. 29, 2013 Revised: Sep. 26, 2013

Accepted: Oct. 08, 2013

Corresponding Author: Dong-II Shin(Sejong University)

E-mail: dshin@sejong.ac.kr

ISSN: 1598-4540 / elSSN: 2287-8211
(C) The Korea Game Society. All rights reserved. This is an open-access article distributed under the terms of the Creative Commons Attribution Non-Commercial License (http://creativecommons.otg/licenses/by-nc/3.0), which permits unrestricted non-commercial use, distribution, and reproduction in any medium, provided the original work is properly cited. 


\section{1. 서 론}

게임 정보기술의 발전은 게임 소프트웨어, 게임 기구 및 컴퓨터 하드웨어의 고성능과 기억공간의 고 용량화, 사용환경의 편의성 및 처리속도의 고속 화, 주변장치와 네트워크, 인터넷 등의 발전으로 게임의 고급화가 진행되었다[1]. 체감형 게임이란 게임 조작의 한 방법으로 사람의 동작에 따라 직 접 프로그램이 제어됨으로써 신체의 움직임을 최대 한 반영하는 게임이다[2]. 따라서 지금까지의 게임 용 인터페이스인 화면, 소리 등 시각과 청각에 기 반을 둔[3] 게임과는 달리 게임과 인간과의 상호작 용은 키보드나 마우스로도 이루어질 수 있다. 체감 형 게임이 부각되기 시작한 것은 닌텐도의 Wii가 개발되면서이다.

닌텐도 $\mathrm{Wii}$ 가 출시되면서 게임에서는 특히 체감 형 인터페이스가 부각되기 시작하였으며, 다양한 감각을 활용하는 인터페이스 개발이 확대되는 추세 이다[2]. 최근 들어 촉각(햅틱폰), 후각(향 발생기), 감성(뇌 인터페이스)등 다양한 감각을 활용하는 인 터페이스 개발이 확대되는 추세이다. 닌텐도 $\mathrm{Wii}$ 의 사례와 같이 손 움직임 등 다감각 인터페이스 기 술을 함께 사용할 경우 보다 실감나고, 직관적인 콘텐츠의 개발이 가능하다.

NUI(Natural User Interface)는 키보드와 마우 스 없이 사용자의 신체부위를 이용한 인터페이스 로, 2006년 Christian Moore[4]가 제스쳐 인식 등 관련 기술에 관한 논의를 위해 오픈리서치 커뮤니 티를 개설하면서 확산되었다[5]. 본 실험에서는 $\mathrm{NUI}$ 공간에서 체감형 게임을 시행하였고, 시행 전 과 후로 사용자의 심전도를 측정하여 스트레스 여 부를 분석하였다.

심전도는 심장에서 흐르는 전기적인 신호로 이 를 측정하여 사용자의 질병의 유-무와 현재의 상 태를 진단할 수 있다. 본 연구에서는 사용자가 체 감형 게임을 할 때 발생하는 심전도(ECG) 신호를 측정하여 스트레스를 분석하였다. [6]에서는 심전도 를 사용하여 스트레스를 측정하고, 바이오피드백
기술을 적용한 사용자 스트레스 해소 여부에 대한 연구를 진행하였다. 심전도 신호는 심장에 흐르는 전기적인 신호를 나타낸 것[7]으로 $\mathrm{P}, \mathrm{QRS}, \mathrm{T}$ 파로 총 다섯 개의 파형으로 나누어진다. 스트레스는 심 전도에서 측정할 수 있는데, 일반적으로 $\mathrm{R}$ 파에서 도출할 수 있다[8].

실험은 스마트 공간으로 분류된 네 개의 공간 중 NUI(Natural User Interface) 공간으로 구성된 게임 룸(Game room)에서 진행하였다. 심전도 데 이터는 게임 시행 전과 후로 나누어 각각 60 초간 측정하였다. 실행된 게임은 NUI 공간에서 사용자 의 동작을 키넥트로 인식하여 화면상에 제시된 태 권 동작을 정확하게 따라서 수행하는지에 대한 여 부를 점수화 하는 방식으로 진행되었다.

심전도 신호 분석에 의해 도출된 스트레스 발생 여부는 게임 콘텐츠의 난이도 자동 조정에 활용될 수 있으며, 적절한 난이도 조절은 사용자의 게임 몰입도를 높이는데 활용이 가능하다[9]. 따라서 본 연구의 결과는 사용자의 몰입감을 높이는 차세대 스마트 콘텐츠 개발에 적용이 가능할 것이다.

\section{2. 스마트 공간의 NUI에서의 체감형 게임}

\section{1 스마트 공간과 NUI}

본 연구에서 제안한 스마트공간은 총 스터디 룸 (study room), 거실(living room), 침실(bed room), 게임 룸(game room)으로 구성되어있다. NUI(Natural User Interface) 기술은 컴퓨터와 사 용자 사이의 간격을 줄여서 사용성을 높여줄 수 있는지 없는지를 결정하는 기술이다. NUI는 키보 드에 기반한 CLI(Command Line Interface), 마우 스에 기반한 GUI(Graphics User Interface)와는 달리 명령어와 사용법을 배우지 않더라도 기존의 사용자가 가진 경험을 기반으로 키보드나 마우스 없이 신체부위를 이용하여 자연스럽게 사용할 수 있는 사용자 인터페이스를 말한다.

따라서 NUI 공간은 이런 사용자 인터페이스를 
활용한 공간으로, 손동작인식, 몸동작 인식, 음성인 식등 사용자가 입력장치에 구애받지 않고 기기를 사용 할 수 있는 공간을 의미한다.



[Fig. 1] NUI Space

본 연구에서는 NUI 공간에서 게임 시행 전과 시 행 후로 나누어 사용자의 심전도를 측정하였다. 전 송 시에는 사용자 정보를 인증하며, 인증 후에 전송 받은 정보를 사용자 프로파일에 저장한다. 측정된 심전도 신호는 자동으로 분석되어 스트레스의 발생 여부가 파악된다. 사용자가 직접 입력한 스트레스 상태 여부를 활용하여 교사학습 방식에 의한 실험 을 진행하였고, 이에 대한 정확도가 도출되었다.

\section{2 체감형 게임}

체감형 게임은 다양한 게임의 장르 중에서도 인 간의 실제 행동과 유사하게 상호작용하는 게임이 다. 조이스틱, 조이패드, 키보드, 마우스 등 입력장 치를 활용한 일반적인 게임들과 달리 체감형 게임 은 핸들조작, 총을 이용한 조준 및 발사, 몸을 이 용한 춤추기 등 실제상황에서 체험할 수 있는 행 동으로 이루어진다[10]. 체감형 게임은 실제 신체 를 사용한 경험에 기반하기 때문에 장비를 활용한 다른 게임과는 차이가 있다. 체감형 게임에서의 체 험은 사용자의 의식과 육체 속에 내면화됨으로써 실제적인 현실로서 인식될 수 있으며, 다양한 사회 적 현상을 유발시키고 있다는 점에서 논의의 대상 이 된다[11]. 현재 체감형 게임은 전 연령층을 대 상으로 정상 성인에게 맞추어 개발되고 있다[12].
또한 게임의 발전에 따라 종류도 다양하게 수많 은 장르로 나눌 수 있다. 아동을 대상으로 만든 줄 넘기게임[13]은 동작인식부분에서 성인과는 다르게 아동이 다양하게 취할 수 있는 동작에 맞추어 "앉 기”, “점프”등을 다양한 컨셉을 잡아 구성하며, 음 향도 아동이 듣는데 거부감 없도록 리듬감을 잡아 구성한다. 체감형 게임은 일반적인 신체동작부분을 데이터화하여 실행 시에 입력 데이터로 활용한다 [10]. 또한 인터랙션 스타일에 따라서 탑승식 체감 형 게임, 포터블 센서를 이용한 체감형 게임, 센서 가 부착된 고정 플랫폼을 이용한 체감형 게임으로 나눌 수 있다[10].

본 연구에서는 NUI 공간에서 게임을 시행하였 다. 게임은 태권도 게임으로 컴퓨터와 사용자간의 대련으로 사용자는 손과 팔 다리를 활용할 수 있 다. 게임은 $4 \mathrm{D}$ 게임 엔진으로 설계하였는데, 게임 엔진은 OpenNI Layer, Synchronizer, Abstract Layer의 모듈로 나뉘며, 세 개의 모듈은 Unity3D 게임 엔진위에서 통합된다. 그리고 IR 센서 기반의 동작인식 기술을 사용하였는데, 1) Joint Angle Recalculation, 2) Joint Position Normalization, 3) Joint Local Rotation으로 구성된다. 1)은 각 조인트 위치 사이의 각을 계산하고, 2)는 조인트의 위치를 정규화 하여 동작을 비교하였다. 그리고 3) 은 키넥트로 부터 들어온 조인트 회전각을 $3 \mathrm{D}$ 기 준모델에 대합하여 조인트의 로컬 회전각으로 동작 을 인식한다.

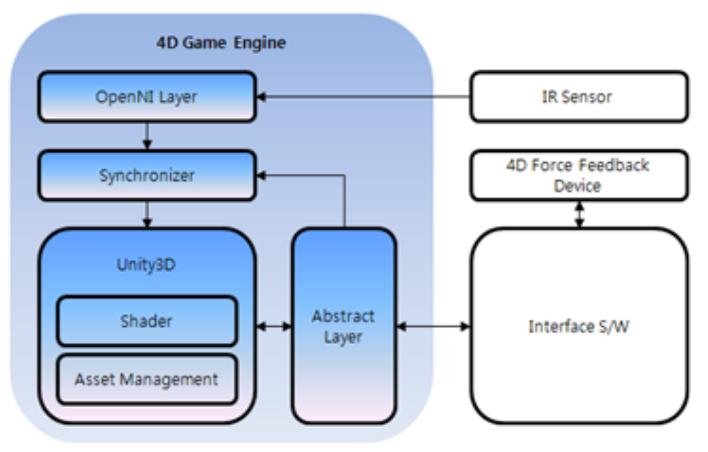

[Fig. 2] Structure of $4 \mathrm{D}$ game engine 


\section{3 게임 환경}

사용자는 NUI 공간의 게임 룸에서 게임을 시행 한다. 게임 시작 전에 사용자는 심전도 신호를 측 정하며 측정한 신호는 사용자 프로파일로 전송된 다. 게임은 사용자가 시스템에 인증과정을 거친뒤 에 시작하며, 게임 시에 취하는 동작들은 키넥트를 통해서 인식된다.

게임은 태권도 동작으로 구성되어 있고, 사용자 와 컴퓨터와의 대련으로 전개된다. 사용자는 먼저 캐릭터를 선택할 수 있는데 남자는 남성형 캐릭터, 여자는 여성형 캐릭터를 선택한다.
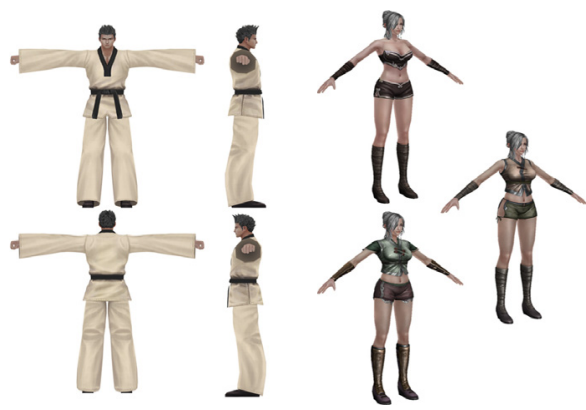

[Fig. 3] Character of game

사용자는 선택한 캐릭터를 사용하여 몬스터와의 대련을 펼친다. 이때 사용자가 취할 수 있는 자세 는 게임에 미리 설정되어 있는 태권도 동작들이다.

[Table 1] Applicable parts of the body

\begin{tabular}{|c|c|}
\hline Body & Applicable parts \\
\hline Punch & $\begin{array}{c}\text { punch, back fist, knife swallow, } \\
\text { knuckle fist, flat fist }\end{array}$ \\
\hline Hand & $\begin{array}{c}\text { hand knife, revers hand knife, } \\
\text { hand edge, palm fist }\end{array}$ \\
\hline Foot & $\begin{array}{c}\text { foot elbow, heel, foot knife, top of } \\
\text { foot, sole, foot knife }\end{array}$ \\
\hline Leg & shank, knee \\
\hline Arm & wrist, elbow \\
\hline
\end{tabular}

[Table 1]은 게임에서 활용할 수 있는 동작들이 고, [Fig. 4]는 사용자가 직접 취하는 동작들을 시 뮬레이션으로 나타내었다. 사용자는 몬스터와 대련 할 때 주어진 동작 중에 본인들이 취하기 편한 동 작을 선택하여 게임을 즐길 수 있다.
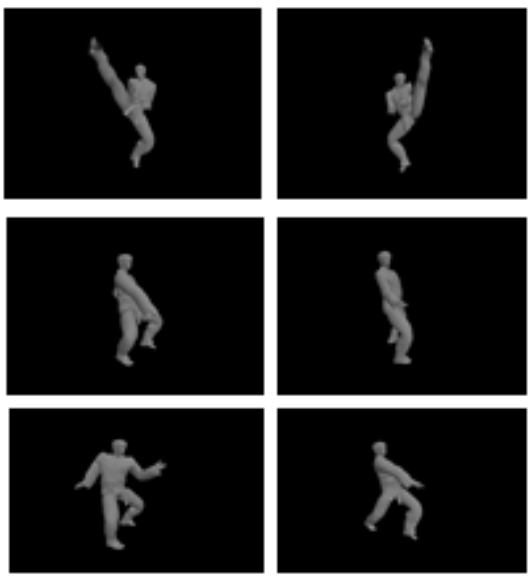

[Fig. 4] Motion of tae-kwon-do

[Fig. 4]의 flow chart는 게임 시작부터 종료까 지의 진행상황을 나타내었다. 사용자는 게임 전에 로그인을 하여 본인인증을 한다. 또한 로그인 서브 메뉴에는 일반적인 사이트에서 제공하는 회원가입 과 탈퇴의 기능도 포함되어 있다. 인증 후 사용자 는 게임을 실행할 수 있으며, 기존에 사용했던 내 역을 사용자 프로파일에서 체크할 수 있다. 이전에 실행했던 내역이 있는 사용자는 게임을 이어서 실 행할 수 있으며, 처음인 사용자는 프로필을 생성하 여 게임을 진행할 수 있다. 프로필 생성 후에 사용 자는 메인메뉴의 서브메뉴들을 사용하여 게임을 진 행할 수 있으며, 스트레스 통계를 통하여 자신이 받은 스트레스 수치와 스트레스를 받지 않은 수치 를 알 수 있다. 게임의 난이도에 따라서 사용자는 스트레스를 받게 되며, 이를 점수로 환산하면 사용 자에 따른 게임의 몰입상태를 알 수 있다[9]. 본 연구에서는 게임 시행 전에 측정한 심전도 신호의 스트레스 상태를 Neutral(평온한 상태)로 분류하였 고, 게임 시행 후의 상태를 NonStress(스트레스 
없음)와 Stress(스트레스 있음)의 두 경우로 분류 하였다.

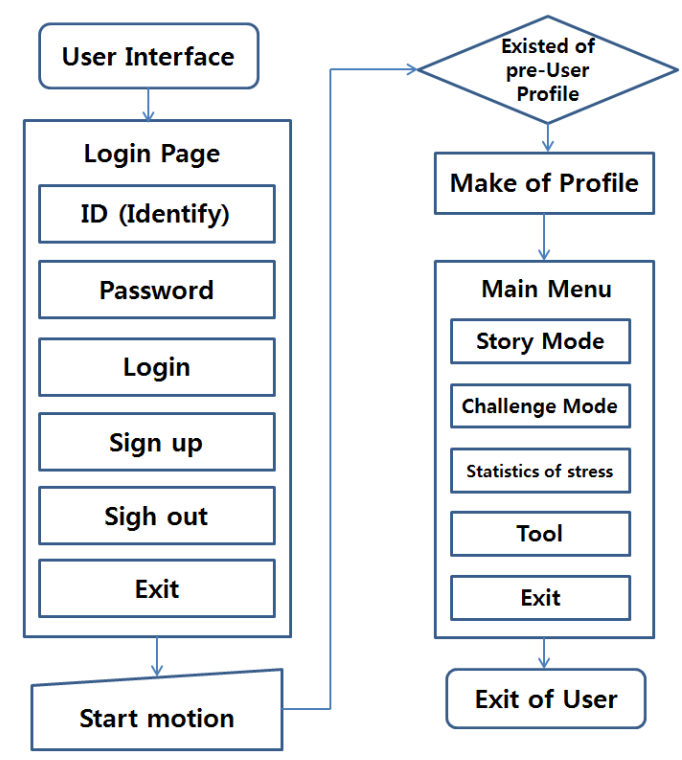

[Fig. 5] Flow Chart of Tangible game

\section{3. 실험방법}

\section{1 실험 알고리즘}

실험은 Tree 알고리즘의 하나인 Random Forest 로 시행하였다. Random Forest는 임의 벡터선택으 로 사용되는 알고리즘으로 Decision Tree 를 위해 특별히 설계된 앙상블 기법이다[14]. 앙상블 기법은 두 개 이상의 알고리즘의 유용한 특징을 합한 머신 러닝기법을 말한다. Random Forest는 많은 결정 트리들로 구성된 분류기이며, 개별 트리들의 결과 클래스들의 최빈값 클래스를 출력한다.

각각의 Decision Tree는 일정한 확률분포로 부 터 생성된 임의의 벡터를 사용한다. 임의의 벡터는 인위적으로 선택한 값이 아닌 임의로 선택한 벡터 의 값을 말한다. 임의 벡터는 트리가 성장할 때 각 노드의 분할을 위해 무작위로 선택된 $\mathrm{F}$ 개의 입력 특징을 전체적으로 조사하는 대신에 선택된 $\mathrm{F}$ 개의
특징으로부터 결정된다[15].

학습할 경우의 수를 $\mathrm{F}$, 분류기의 변수들의 수를 $\mathrm{M}$ 이라고 가정하면, 입력 변수 $\mathrm{m}$ 은 트리의 노드에 서 결정을 내릴 때 사용되며 $\mathrm{m}$ 은 $\mathrm{M}$ 의 값보다 작 아야 한다. 전체 $\mathrm{F}$ 학습 데이터로부터 $\mathrm{F}$ 번 랜덤 샘플링을 통하여 학습 데이터를 생성하는데, 한번 뽑은 데이터도 다시 뽑힐 수 있도록 복원추출을 하고, 나머지 예제 데이터들은 트리의 오류를 검증 할 때 사용된다. 트리의 각 노드에 대하여, 랜덤으 로 $\mathrm{m}$ 개의 변수들을 선택하고 $\mathrm{m}$ 개의 변수들에 기 준하여 학습집합에서의 최고의 트리를 생성한다. 그리고 개별 트리들은 가지치기를 하지 않고 끝까 지 트리를 생성한다[16]. Random Forest의 장점은 학습속도가 빠르고, 불완전한 값들이 포함되어 있 어도 좋은 성능을 보인다는 것이다.

그러나 불완전한 값들이 포함되어 경우 에는 그 로인해 중복된 값에 의해서 오버피팅(Overfitting) 현상이 발생할 수 있다. 오버피팅(Overfitting) 현 상이 생기면 정확한 값 즉, 정확도(Accuracy)에 대한 신뢰도가 떨어질 수 있으므로 본 논문에서는 정확도를 개선하기 위하여 $\mathrm{FP}-$ 성장 알고리즘이 적 용된 변형 Random Forest 알고리즘을 사용하였 다. $\mathrm{FP}-$ 성장 알고리즘은 상향식 방법으로 트리를 탐험하여 $\mathrm{FP}$ 트리에서 가장 빈번하게 발생하는 빈 발항목 집합들을 생성한다[15].

[Table 2] Frequent Itemsets of FP-Tree

\begin{tabular}{|c|c|}
\hline Suffix & Frequent Itemsets \\
\hline Neutral & $\{\mathrm{N}\},\{\mathrm{N}, \mathrm{I}\},\{\mathrm{I}\}$ \\
\hline NonStress & $\{\mathrm{I}, \mathrm{A}\},\{\mathrm{A}\}$ \\
\hline Stress & $\{\mathrm{V}\}$ \\
\hline
\end{tabular}

본 연구에서는 심전도 신호의 상태를 Neutral (평온한 상태), NonStress(스트레스 없음), Stress (스트레스 있음)로 세 개의 속성으로 구분하였다. Neutral은 체감형 게임을 하기 전의 상태이며, NonStress와 Stress는 게임 후의 상태를 나타낸 다. $\mathrm{FP}$ 트리는 해당 속성에서 빈번하게 발생한 애 
트리뷰트를 빈발항목집합으로 구성하여 탐지하였 다. $\mathrm{FP}$ 트리는 분할정복전략(divide-and-conquer) 을 사용함으로써 문제를 더 작은 부분문제들로 분 할한다. Fig 6는 $\mathrm{FP}-$ 성장 알고리즘을 실험에 적 용시의 빈발항목집합생성을 나타냈으며, N, I는 Neutral에서 나타나는 빈발항목 집합을 나타낸다. Neutral은 평온한 상태로 아무 자극이 주어지지 않은 상태를 의미한다. NonStress는 스트레스를 받지 않은 상태이며, Neutral과는 달리 자극을 받 는 상태이다. Stress는 V의 항목만을 가지며, 온전 히 자극을 통해 스트레스를 받고 있는 상태를 의 미한다.

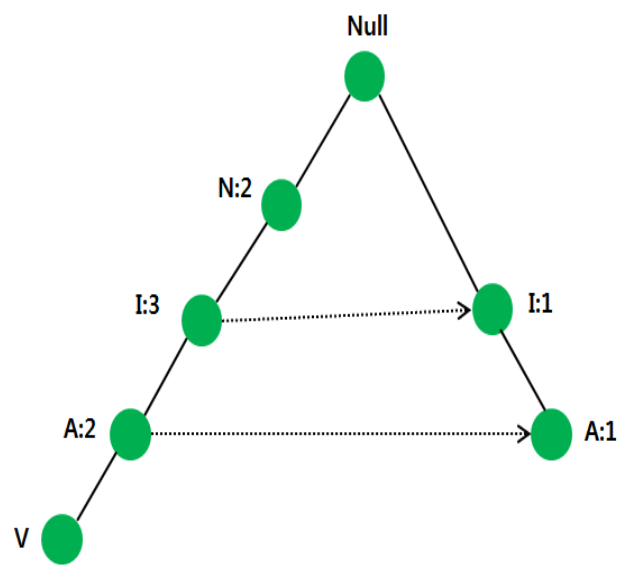

[Fig. 6] Structure of FP-Tree

\section{2 수식}

본 실험에서는 Accuracy(정확도), Sensitivity (민감도), Specificity(특이도)를 도출하였다. 이는 TP(True Positive), TN(True Negative), FP(False Positive) 그리고 FN(False Negative) 을 먼저 도출한 후에 아래 수식을 사용하여 계산 한다.

$$
\text { Accuracy }=\frac{T P+T N}{T P+T N+F P+F N} \quad \text { (eq. 1) }
$$

$$
\begin{aligned}
& \text { Sensitivity }=\frac{T P}{T P+F N} \\
& \text { Specificity }=\frac{T N}{T N+F P}
\end{aligned}
$$

Accuracy, Sensitivity, Specificity는 의학 통계 분석에서 사용되는 진단정확도의 표현방법이다. Sensitivity는 Gold standard $(\mathrm{TP}+\mathrm{FN})$ 가 있는 것 중에서 있다고 판단하는 확률을 뜻하며, Specificity는 Gold standard $(\mathrm{TP}+\mathrm{FN})$ 가 없는 것 중에서 없다고 판단하는 확률이다. 그리고 Accuracy는 Gold standard $(\mathrm{TP}+\mathrm{FN})$ 가 있는 것을 있다고 판단하고 Gold standard $(\mathrm{TP}+\mathrm{FN})$ 가 없는 것은 없다고 판단하는 확률을 말한다.

\section{3 실험결과}

실험과정은 게임 시행 전에 측정한 심전도 신호 를 사용자 프로파일에 전송하고, 시행 후에 측정한 신호를 사용자 프로파일에 전송한다. 전송받은 신호 를 전처리 과정(pre-processing)을 통하여 지저선 잡음(baseline wondering)과 노이즈를 제거하여 스 트레스신호를 추출한다. 추출한 신호는 데이터를 수 치화하여 Random Forest 분류기로 실험한다.

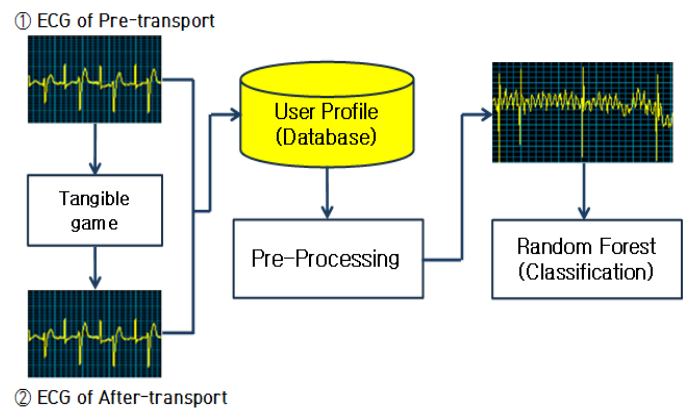

[Fig. 7] Processing of experiment

실험자는 19 세에서 22 세까지의 대학생 남녀 각 각 10 명을 상대로 모두 20 명에게 시행하였다. 본 연구에서 심전도 신호는 각각 게임 전과 후로 나 
- A Study on a Stress Measurement Algorithm Based on ECG Analysis of NUI-applied Tangible Game Users -

누어서 60 초에 걸쳐서 추출하였다. 실험은 기존의 Random Forest 트리 알고리즘과 정확도 개선을 위해 $\mathrm{FP}-$ tree를 적용한 변형 알고리즘의 Stress의 실험결과를 [Table 3]에 나타내었다. [Table 3]은 실험에 참여한 사용자 20 명의 전체실험결과의 평 균이며, 게임 시행 전과 후의 결과 중에서 스트레 스가 높게 도출된 시행 후의 결과만을 나타내었다.

[Table 3] Result of Stress

\begin{tabular}{|c|c|c|}
\hline & Not-Modified & Modified \\
\hline SEN & $98.82 \%$ & $98.83 \%$ \\
\hline SPE & $90.9 \%$ & $100 \%$ \\
\hline ACC & $97.91 \%$ & $98.95 \%$ \\
\hline Mean & $95.87 \%$ & $99.26 \%$ \\
\hline
\end{tabular}

Not-modified는 수정하지 않은 기존의 Random Forest 알고리즘에 대한 결과이고, Modified는 수정 된 알고리즘에 대한 결과이다. $\mathrm{SEN}$ (Sensitivity)는 민감도, $\mathrm{SPE}$ (Specificity)는 특이도, 그리고 $\mathrm{ACC}$ (Accuracy)는 정확도를 나타낸다. 정확도 결과 를 살펴보면, Modified의 결과가 Not-modified의 결과보다 $1.04 \%$ 높은 결과를 도출하였다. 따라서 기존의 알고리즘보다 변형 후 알고리즘의 성능이 조 금 더 개선되었음을 알 수 있었다.

\section{4. 결론 및 토의}

본 연구에서는 스마트공간으로 분류한 게임 룸 을 NUI공간으로 구성하여 체감형 게임을 시행하였 고, 게임 시행 전과 후로 나누어 사용자의 심전도 신호를 측정하여 스트레스를 분석하였다. 시행한 체감형 게임은 태권도 게임으로 컴퓨터와 사용자간 의 대련으로 구성되었다. 본 연구의 목표인 체감형 게임에서의 심전도 측정은 기존에 실험된 바가 없 는 최초의 시도이며, 분류기 알고리즘의 정확도 개 선에 초점을 두었다. 실험은 측정한 신호를 전처리 하여 스트레스 상태를 도출하였고, 이를 데이터로 구성하여 분류기 실험을 하였다. 분류기 실험은
트리 알고리즘인 Random Forest를 사용하였고, 기존의 알고리즘과 정확도의 개선을 위해 알고리즘 을 변형한 실험을 같이 진행하였다. 실험결과는 변 형알고리즘의 결과가 기존 알고리즘 보다 $1.04 \%$ 높은 결과를 도출하였다.

향후에는 태권도 게임 외에도 다른 장르 즉, 롤 플레잉 게임 등 난위도가 높은 게임으로 구현하여 시행할 예정이다. 사용자의 상태는 심전도를 활용 한 스트레스를 측정하였는데, 이후에는 뇌파를 활 용한 스트레스 측정 및 감정인식 부분에 관한 연 구가 필요하다.

\section{ACKNOWLEDGMENTS}

"This research was supported by the MSIP(Ministry of Science, ICT and Future Planning), Korea, under the ITRC(Information Technology Research Center)) support program (NIPA-2013-H0301-13-4007) supervised by the NIPA(National IT Industry Promotion Agency)"

\section{REFERENCES}

[1] Sang-Hyuk Ahn, Eun-Ju Kim and Chang-Geun Song, "Investigation of a trajectory of a golf ball for Interactive 3D Golf Game", KIISE, Vol.6, pp. 88-90, 2006.

[2] Kang-Soo Kim, Yong-Hee Han, Won-Beom Jung, Young-Ho Lee, Jung-Hoon Kang, Heung-Ho Choi and Chi-Woong Mun, "Technical Development of Interactive Game Interface Using Multi-Channel EMG Signal", Korea Game Society, Vol.10, No.5, pp. 65-73, 2010.

[3] Yoon-Seok Han, Eun-Seok Kim, Hyun-Cheol Lee, Beom-Seok Kim, Jea-Hong Joo and Gi-Taek Hur, "Prototype Tangible Bicycle Game Contents for the Silver Generation ", The Korea Contents Society, Vol.9 No.8, pp. 166-177, 2009. 
[4] C. Moore, "New Community Open". NUI Group Community :

http://nuigroup.com/log/comments/forums_lau nched/

[5] S. S. Lee and G. P. Lee, "A Model of Natural User Interface Design", HCI, pp. 962-965, 2011.

[6] Kil-Sang Yoo and Woo-Hyung Lee, "A design of the Biofeedback Serious Game using Electrocardiography", Korean Society for Computer Game, Vol.2, No.23, pp. 283-288, 2010.

[7] K. S. Park, B. H. Cho, D. H. Lee, S. H. Song, J. S. Lee, Y. J. Chee, I. Y. Kim, and S. I. Kim, "Hierarchical Classification of ECG Beat Using Higher Order Statistics and Hermite Model," J Kor Soc Med Informatics, Vol.15, pp.117-131, 2009.

[8] LAXTHA : http://www.laxtha.com/

[9] Sangwon Um, Taeyong Kim and Jongsoo Choi, "Dynamic Algorithm for Game difficulty control", HCI, pp. 193-200, 2003.

[10] Won-Hyoung Kang, "Handheld Augmented Reality Game System Using Dynamic Environment", KAIST, Master's Thesis, 2007.

[11] Kim-Jae Young and Sung-Jung Hwan, "The Formation of New Game Generation in Game-Extended Space : Focused on the Experience Game", Korea Game Society, Vol.10, No.5, pp. 3-13, 2010.

[12] Jae-kwon Yoo and Kyoung-mi Lee, "Children's Interactive Game using RFID and Speech Interface", HCI Korea, pp. 564-566, 2011.

[13] Hye-min Won and Kyoung-Mi Lee, "Interactive rope skipping game for early child", The Korea Contents Society, pp. 58-60, 2010.

[14] Ian H. Witten, Eibe Frank and Mark A. Hall, "Datamining : Practical Machine Learning Tools and Techniques", 3rd Ed, Morgan Kaufmann, 2011.

[15] P. N. Tan, M. Steinbach and V. Kumar, "Introduction to Data Mining", 1st Ed, pp. 283-285, Addison-Wesley, 2006.

[16] S.H. Park, "Sentence Boundary Detection Using Machine Learning Techniques", Korea University M.S, 2008.

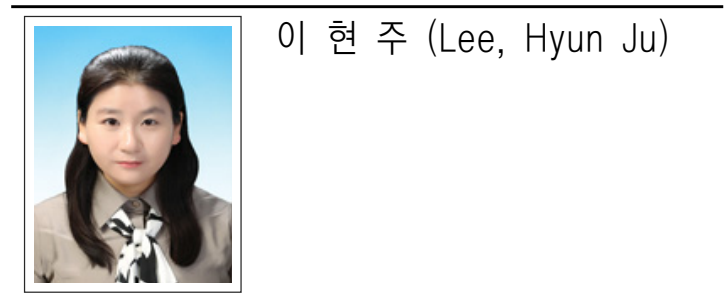

세종대학교 일반대학원 컴퓨터공학과 박사과정

관심분야 : Brain-Wave, $\mathrm{BCI}, \mathrm{Bio}$-information, $\mathrm{HCI}$, ECG

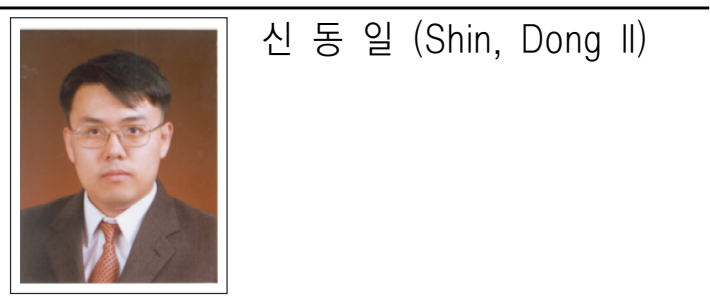

세종대학교 컴퓨터공학과 교수

관심분야 : $\mathrm{HCI}, \mathrm{BCI}$, 무선인터넷, 게임엔진, $\mathrm{CSCW}$ etc.

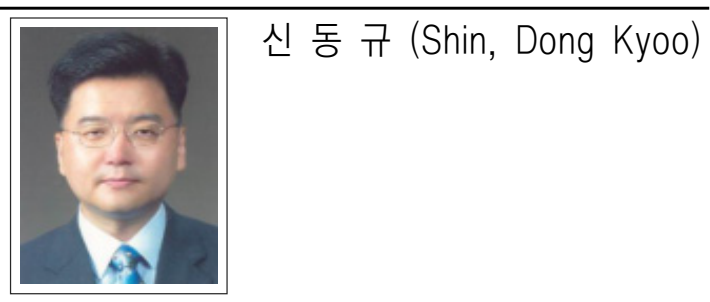

세종대학교 컴퓨터공학과 교수

관심분야 : $\mathrm{BCI}, \mathrm{XML}$, 보안, 전자상거래, $\mathrm{MPEG}$ etc. 